\title{
La presse et le pouvoir de Louis XIII à Napoléon Ier.
}

\section{Serge Bianchi}

\section{OpenEdition}

Journals

Édition électronique

URL : https://journals.openedition.org/ahrf/1149

DOI : 10.4000/ahrf.1149

ISSN : 1952-403X

Éditeur :

Armand Colin, Société des études robespierristes

Édition imprimée

Date de publication : 1 septembre 2001

Pagination : 138-140

ISSN : 0003-4436

\section{Référence électronique}

Serge Bianchi, « La presse et le pouvoir de Louis XIII à Napoléon ler. », Annales historiques de la

Révolution française [En ligne], 325 | juillet-septembre 2001, mis en ligne le 22 avril 2004, consulté le 23 avril 2022. URL : http://journals.openedition.org/ahrf/1149 ; DOI : https://doi.org/10.4000/ahrf.1149

Ce document a été généré automatiquement le 23 avril 2022.

Tous droits réservés 


\title{
La presse et le pouvoir de Louis XIII à Napoléon Ier.
}

\author{
Serge Bianchi
}

\section{RÉFÉRENCE}

Jean-Paul Bertaud, La presse et le pouvoir de Louis XIII à Napoléon Ier, Librairie académique Perrin, 2000, 278 pages.

1 Après une fresque consacrée à la guerre et à la société militaire, Jean-Paul Bertaud s'interroge sur les relations entre la presse et le pouvoir, sur une durée comparable à l'ouvrage précédent, puisqu'elle traite de la genèse de la Gazette de Renaudot (1631) à la fin de l'Empire: presque un retour aux sources, quand le pouvoir ne tolère plus qu'une poignée de périodiques aptes à autocélébrer le régime moribond. Dans le plan se succèdent des séquences chronologiques («les_mots_embastillés» jusque 1789, pour la Révolution et l'Empire), et des séquences thématiques transversales: la fabrication du journal, les milieux des journalistes et des lecteurs, les caractères et les contenus de la presse, l'éducation des campagnes, la presse des armées et la presse féminine (voire féministe). Il est vrai que l'auteur peut s'appuyer sur la connaissance solide de ces questions, puisée dans ses recherches sur la presse royaliste et cordelière, la vie quotidienne, le monde des armées et de nombreuses maîtrises mentionnées. Une première lecture permet de dégager deux mérites essentiels. D'une part, le souci d'inscription dans une durée séculaire aide à cerner les logiques communes à différents régimes, de comparer les ambitions d'un Richelieu, omniprésent dans la Gazette ou d'un Napoléon, dictant le contenu du Bulletin de la grande Armée. Mais l'originalité de la période révolutionnaire n'en est que mieux mise en valeur, non pas dans un panorama des titres et des auteurs, mais à la suite d'analyses suggestives des régimes successifs de la presse, des continuités techniques, des vicissitudes du métier de journaliste. On voit surgir après la «semi-liberté» des années 1760 et la «liberté» de 1788 l'explosion des titres, l'émergence d'une opinion publique avide de nouvelles, la création d'une presse 
d'opinion qui embarrasse les régimes successifs, tant elle rechigne à se faire subventionner et à célébrer les gouvernements de l'anII comme de l'anVII.

2 Les paris de l'auteur peuvent parfois «frustrer» les spécialistes de la décennie révolutionnaire, tant les études se sont multipliées sur de nouveaux chantiers de la presse (Elyada, Feyel), au point de souhaiter une première synthèse, faisant le point des acquis depuis les travaux «classiques» des années 1950. Jean-Paul Bertaud s'adresse à un public large en conciliant un style alerte (exempt de jargon) et une édition sans notes ou appareil critique avec la précision des données et des dates. Il en résulte un ouvrage difficile à classer, entre une histoire érudite de la presse et celle de son «quotidien» à l'épreuve de la politique. C'est dans ce domaine que les apports sont les plus remarquables. Après la Déclaration des droits de l'homme et de publier, la liberté est remise en cause dans les moments critiques, après la fuite du roi, la chute de la monarchie, la Terreur et fructidor anV. Mais la statistique des périodiques permet de préciser la portée de ces différentes législations. Une presse provinciale apparaît dans les années 1770-1780 avec les Affiches (21 en neuf années), mais l'opinion ne trouve son espace qu'à partir de juillet 1788 et la campagne pour les États généraux, autour d'une centaine de pamphlets non censurés. Si 184 titres sortent à Paris en 1789, il paraît encore 79 périodiques en l'an VII (1799) mais 4 dans la capitale en 1814! Il est possible de suivre certains tirages, des quelques milliers de privilégiés en 1631 (60000 en 1763?) aux quelque 800000 abonnés de 1794, en un survol suggestif de la massification du lectorat, qui correspond à une diversification du contenu. Les cabinets de lectures (520 à Paris et en province dans les années 1780) préparent les lectures publiques de la rue et des sociétés populaires, quand la moitié des citoyens actifs a accès d'une manière ou d'une autre à une information «civique» ou technique. Mais dans le même temps les techniques restent "classiques», le prix du papier et de l'impression flambe, et les marges de profit augmentent avec le tirage. Au-delà de 5000 exemplaires l'imprimeur est assuré de gains appréciables, si le contenu politique ne gêne pas le régime en place. Après 1815 , une révolution technique s'amorce qui fera de la presse le principal vecteur de l'opinion, de la formation des partis et de l'expression des débats politiques.

3 Un autre mérite de l'ouvrage est la réflexion sur le métier de journaliste, si bien amorcée dans la Préface de Théophraste Renaudot. Passé le discrédit (ambigu) des Lumières face au «philosophe», le journaliste voit son statut modifié par la Révolution au point de devenir une «puissance de la terre», selon Camille Desmoulins. La presse devient, malgré ses abus, un contre-pouvoir, un réactif à toutes les journées révolutionnaires, de la Nuit du 4août au massacre du Champ-de-Mars. Le journaliste se veut «sentinelle», puis la conscience civique des habitants de la ville... et des campagnes. La volonté d'éduquer les hameaux est constante, de la Feuille villageoise qui désire «enraciner la Constitution dans tous les villages de France» à la Feuille d'instruction populaire de Lakanal. Les tirages de ces périodiques destinés aux ruraux sont considérables (jusqu'à 15000 abonnés), à condition de savoir que les paysans ne les lisent guère - tout en étant "informés par les "clartés intermédiaires" -, et que les priorités restent gouvernementales: payer les contributions et accepter le régime représentatif, dans le cadre de la liberté économique... Il est possible que la républicanisation des militaires soit plus efficace, par la lecture du Bulletin de la Convention, la Feuille de salut public et le Père Duchesne. La différence avec les «canards» de la Grande Guerre est évidente, avant que les Bulletins de la Grande Armée n'en modifient le contenu. Jean-Paul Bertaud introduit sur toutes ces questions des analyses 
maîtrisées, suggestives et renouvelées par l'apport de recherches en partie inédites, telles les batailles électorales de presse de 1791 et 1797.

Quelques regrets, ponctuels et mineurs, peuvent émailler cette lecture stimulante. Les promesses du titre (la presse et le pouvoir) s'estompent parfois au fil de chapitres plus techniques ou spécialisés. L'équilibre des périodes abordées est rompu au profit de la Révolution, qui s'en plaindrait? Toutefois, il nous semble que le lancement de la Gazette comporte la plupart des interrogations et des ambiguités de la presse moderne et contemporaine, et que la période des Lumières pourrait appeler d'autres développements sur les mutations du public, les formes de lecture... Le pittoresque de certains portraits et des morceaux de bravoure littéraires, plutôt réussis, peuvent masquer certaines logiques, mais c'est probablement lié aux priorités de la collection. Le dernier chapitre sur la presse féminine peut être apprécié de diverses manières. On pourrait insister sur l'aspect novateur, ou y voir un effet de mode, n'apportant pas une contribution fondamentale à la perspective d'ensemble de l'ouvrage. Mais l'essentiel n'est pas là. Sortant des sentiers battus de la presse révolutionnaire, Jean-Paul Bertaud réussit à renouveler le genre, en évitant les portraits (connus) de Marat ou d'Hébert, les analyses trop institutionnelles. Il instruit en divertissant, un tour de force sur des thèmes comme la presse du Directoire, les tentatives de contrôle par les régimes successifs, les synthèses sur les lecteurs (page 124), l'évolution des coûts de production. Ajoutons qu'à l'épreuve des cours universitaires, l'ouvrage se révèle être une véritable mine de références, ce qui nous paraît valider le pari initial engagé par l'auteur, de ce mélange subtil d'érudition cachée et d'exercice de style qui en fait toute l'originalité... 